\title{
ANÁLISE DE DISCURSO EM ESTUDO SOBRE ADOLESCENTES COM NECESSIDADES ESPECIAIS DE SAÚDE
}

\author{
Andressa da Silveira ${ }^{1}$ e Eliane Tatsch Neves $^{2}$ \\ 1,2Universidade Federal de Santa Maria, Brasil. 'andressadasilveira@gmail.com ²elianeves03@gmail.com
}

Resumo. Introdução: A análise de discurso é uma possibilidade metodólogica de aprodundamento das matrizes históricas, ideológicas e culturais de efeitos de sentido de textos produzidos. Objetivo: Relatar a experiência sobre a utilização da análise de discurso na corrente francesa (pecheutiana) em estudo de enfermagem com adolescentes. Relato de experiência/Desenvolvimento: Relato de experiência, sobre estudo qualitativo, realizado com adolescentes que vivem com necessidades especiais de saúde. A análise de discurso na corrente francesa é utilizada para a análise de entrevistas semiestruturadas, realizou-se a dupla transcrição, empregou-se as ferramentas analíticas que dão movimento ao texto e aplicação das figuras de linguagem. A análise de discurso é uma estratégia que apresenta possibilidades analíticas nos momentos de silenciamento, na presença das emoções, do conhecimento novo que surge nos discursos dos participantes. A cultura, as matrizes sociais, o momento em que as enunciações são verbalizadas tem representação significativa nesta modalidade de análise, em que o discurso é visto com profundidade e não é avaliado pelo seu conteúdo. Conclusões: A análise de discurso pecheutiana é um método de análise favorável para olhar com profundidade para temas sensíveis, na saúde do adolescente, que valorizam a dimensão subjetiva, as experiências de cada participante e que não podem ser quantificadas.

Palavras-chave: Pesquisa Qualitativa; Discurso; Enfermagem; Metodologia.

\section{DISCOURSE ANALYSIS IN A STUDY ON ADOLESCENTS WITH SPECIAL HEALTH NEEDS}

\begin{abstract}
Introduction: Discourse analysis is a methodological possibility of deepening the historical, ideological and cultural matrices of the effects of the meaning of texts produced. Objective: To report the experience on the use of discourse analysis in the French (Pecheutian) current in a nursing study with adolescents. Method: Experience report on a qualitative study conducted with adolescents who live with special health needs. Discourse analysis in the French current is used for the analysis of semi-structured interviews, a double transcription was made, the analytical tools that give movement to the text and application of figures of speech. Experience / Development report: Discourse analysis is an analysis strategy that presents analytical possibilities in moments of silence, in the presence of emotions, of the new knowledge that appears in the participants' speeches. Culture, social matrices, the moment when the utterances are verbalized have significant representation in this type of analysis, in which the discourse is seen in depth and is not evaluated by its content. Conclusions: Pecheutian discourse analysis is a favorable method of analysis to look in depth at sensitive issues in adolescent health, which value the subjective dimension, the experiences of each participant and which cannot be quantified.
\end{abstract}

Keywords: Qualitative Research; Address; Nursing; Methodology.

\section{INTRODUÇÃO}

Em 1960, na França, o filósofo Michel Pêcheux desenvolveu uma teoria sobre o discurso, denominada de Análise de Discurso (AD). Essa teoria explora a posição teórica da produção discursiva, ocorre a ruptura intelectual e a linguagem passa a ser vista como um ramo complexo. Neste período, extrapola-se a ideia de que o sentido é significado apenas pelo 
conteúdo, redirecionando-se a análise para o entendimento do funcionamento de um texto. A leitura passa a não ser mais concebida como uma ferramenta de decodificação, mas como a construção de um dispositivo teórico (Pêcheux, 2014; Rolim, Sancho, La-Rotta, Fernandez, Figueiredo, Friestino \& Corrêa, 2018; Brandão, 2012; Orlandi, 2015; Lima, Vieira, Gomes \& Silveira, 2017).

Pêcheux propôs um campo de investigação, capaz de integrar a análise das condições de produção do discurso aos processos discursivos (Brandão 2012; Lima et al., 2017). A AD propõe contribuir para sedimentar a coerência necessária na apreensão das falas além de suas aparentes superficialidades e linearidades (Lima, Vieira, Gomes \& Silveira, 2017).

A partir da introdução da análise de discurso de Pêcheux, é refletida a relação existente entre língua/sujeito/história ou língua/ideologia, com pilares fundamentados no processo social, cultural e histórico, onde o discurso é produzido (Caregnato \& Mutti, 2006).

No cenário Brasileiro, a partir de 1970, Eni Orlandi destaca-se pela difusão da AD na corrente pecheutiana (Rolim et al., 2018). Ressalta-se, que existem diferentes correntes de pensamentos sobre a $A D$, todas possuem como interesse comum a investigação sobre a linguagem (Schiavon, Oliveira, Andrade \& Gonçalves, 2017). Os estudos que apresentam a relação entre a língua e a ideologia, onde o discurso ocupa lugar de observação, constitui o ramo de pesquisas filiadas na $A D$ francesa, que ganhou força, como procedimento de análise, em diversos lugares do mundo.

Os estudos discursivos têm o objetivo de pensar o sentido, dimensionado no tempo e no espaço das práticas humanas, descentrando a noção de sujeito e relativizando a autonomia do objeto da linguística (Rolim et al., 2018). Na AD, o discurso é resultado da interpelação entre a língua e a ideologia, o homem e a história. É uma construção social atrelada à materialidade dos objetos de conhecimento e às modalidades de intervenção da linguagem no processo de produção/reprodução de conhecimento (Orlandi 2015; Lima et al., 2017).

A AD francesa ou pecheutiana, considera que a fala não é transparente e literal, sua aplicação possibilita a identificação das regras que delimitam o que pode ser dito, em um dado contexto. Esse referencial e método de análise, tornam-se capazes de contribuir, para a qualificação da pesquisa de enfermagem (Lima et al., 2017). Consiste em uma proposta de análise que busca superar a apreensão linear da linguagem exteriorizada, em seu caráter 
de superficialidade; almeja compreendê-la de forma articulada às suas condições de produção (Brandão, 2012; Orlandi, 2015; Lima et al., 2017).

Frente ao exposto, objetiva-se relatar a experiência sobre a utilização da análise de discurso na corrente francesa (pecheutiana) em estudo de enfermagem com adolescentes.

\section{RELATO DA EXPERIÊNCIA/DESENVOLVIMENTO}

Trata-se de um relato de experiência sobre a utilização da AD proposta por Michel Pêcheux, para análise de pesquisa qualitativa realizada com adolescentes, entre 12 a 18 anos de idade incompletos, que possuem necessidades especiais de saúde, em condições de verbalizar.

Foram desenvolvidas 35 entrevistas, semiestruturadas, individuais, compostas pela carcaterização dos participantes, dimensão de saúde, social e objetiva. Empregou-se ainda, a construção individual de genograma e ecomapa, com intuito de apresentar as redes de cuidados dos adolescentes.

A produção de dados ocorreu de forma voluntária, em sala anexa ao ambulatório. As falas foram áudio gravadas em mídia digital, duplamente transcritas e posteriormente submetidas a AD pecheutiana. Realizou-se a dupla transcrição, empregou-se as ferramentas analíticas que dão movimento ao texto por meio de uma legenda elaborada pela autora do estudo. Entre os símbolos utilizados, destacam-se: /: pausa curta; //: pausa longa; //: pausa muito longa; ...: pensamento incompleto; \#: interrupção; [...]: recorte da enunciação e (texto): comentários da pesquisadora.

Posteriormente, aplicou-se os dispositivos analíticos: metáfora, polissemia, paráfrase, interdiscurso e silenciamento. Para esta etapa foi utilizada a análise cromática, a fim de auxiliar na identificação do sentido atribuído ao discurso proferido pelos adolescentes.

A etapa seguinte, foi delineada por meio dos comentários analíticos, a partir dos sentidos que emergiram das enunciações. Neste momento, foram formados temas geradores e a sua relação com os resultados. Por fim, foi composto o quadro síntese, com os temas geradores e os comentários analíticos, que compuseram as categorias da pesquisa.

Ressalta-se, o potencial da AD pecheutiana, em relação à subjetividade dos adolescentes, seu processo histórico e social em relação a necessidade de cuidados especiais de saúde, e 
o desejo de serem reconhecidos, por suas potencialidades. Os adolescentes com necessidades especiais de saúde necessitam de cuidados específicos de saúde para sua sobrevivência, que vão além dos cuidados requeridos por outros adolescentes, passam por repetidas hospitalizações e percorrem uma longa trajetória em busca de atenção/cuidados para as demandas de saúde.

O grupo de adolescentes deste estudo, possuía internalizado o interdiscurso, de que deveriam aprender a conviver com as demandas de cuidados. As formações discursivas, o silêncio e o não dito revelam o medo do adolescente ser rotulado como diferente, diante das condições de cronicidade.

Algumas expressões utilizadas pelos adolescentes, como "não incomoda", "mudou tudo quanto é coisa" e "eu sempre tive vontade", reforçam a alternância entre o desenvolvimento de seu cuidado, as restrições e o vivido dos adolescentes.

A oferta de escuta sensível, às necessidades de saúde dos adolescentes, revela o desejo de serem reconhecidos para além dos cuidados de saúde. Os participantes trouxeram significados diversos sobre o vivido da adolescência, com necessidade especial de saúde. Enfatizando em seus genogramas e ecomapas, a conformação dos laços sociais, a importância do sentimento de pertencimento a grupos compostos por outros adolescentes e viver a adolescência com naturalidade. Os efeitos discursivos apresentam ênfase nas metáforas presentes nas falas sobre cuidado, nas paráfrases quando os adolescentes replicam as orientações dos profissionais de saúde, na polissemia sobre a naturalidade e o processo de autonomia almejada. Outros discursos apresentaram necessidades de cuidados e restrições/limitações, impostas pela condição de saúde. Os adolescentes questionavam suas (im)possibilidades de viver a adolescência como algo natural e o cuidado presente em seu cotidiano.

O somente teve início a partir da aprovação pelo Comitê de Ética em Pesquisa (CEP) da Universidade Federal de Santa Maria, com aprovação sob número CAAE 57774916.7.0000.5346 e Parecer número 1.673.887.

\section{DISCUSSÃO}

$\mathrm{Na}$ Enfermagem, a utilização da AD como ferramenta de análise de dados qualitativos, permite descortinar um universo que vai além dos significados, possibilita compreender o 
que se apresenta além do discurso. Sua utilização, possibilita uma análise mais aprofundada dos diferentes objetos de estudo na área da saúde, de forma a propiciar uma melhor compreensão dos sujeitos, dos sistemas, das relações de poder, a partir dos sentidos atribuídos em suas falas (Machado et al., 2016).

A AD preocupa-se em compreender os sentidos que o sujeito manifesta através do seu discurso; Pode-se dizer que na $A D$, a linguagem não é transparente, mas opaca. Desta forma, a AD trabalha com o sentido e não com o conteúdo (Caregnato \& Mutti, 2006).

O analista de discurso não procura o sentido "verdadeiro", mas a compreensão dos processos em que os sentidos se estabilizam, em sua materialidade linguística e histórica. $A$ ideologia não se apreende e o inconsciente não é controlado por meio do saber. Para a Análise de Discurso, a ideologia não é ocultação, visão de mundo, ilusão, mas filiação de sentidos, direção da interpretação (Rolim et al., 2018).

O processo da $A D$ tem como princípio os conceitos de sujeito, linguagem e discurso que estão presentes desde a formulação do problema da pesquisa. E é a partir deles que o corpus, a fala materializada em entrevistas é analisado (Orlandi 2015; Lima et al., 2017; Gomes, 2007). Os dispositivos analíticos utilizados na produção científica possibilitaram explicitar os efeitos de produção do sentido utilizados pelos participantes nas entrevistas (Machado, Rossi, Rodrigues, Pacheco, Arantes \& Rodrigues 2016).

O interdiscurso significa os saberes constituídos na memória do dizer; sentidos do que é dizível e circula na sociedade; saberes que existem antes do sujeito; saberes préconstruídos constituídos pela construção coletiva. O discurso é organizado a partir de um conjunto de representações, que configuram determinados pensamentos sociais que são ativados. Possui uma exterioridade que deve ser compreendida como forma de melhor delimitação do sentido produzido, de que existe uma coerência interna do discurso aprofundado, que só pode ser compreendida levando-se em consideração as representações, que influenciam a produção (Gomes, 2015).

Os sentidos são histórico e socialmente construídos e, portanto, estão determinados pelas posições ideológicas existentes no processo sócio histórico em que os discursos são produzidos (Rolim et al., 2018). As condições de produção do discurso é um conceito fundamental à $A D$, onde se pode observar a presença dos elementos sociais, grupais, contextuais, políticos e culturais que influenciam no dito e o não-dito (Gomes, 2015). 
O referencial de $A D$ não deve ser visto apenas como metodologia, mas como disciplina de interpretação fundada pela intersecção de epistemologias distintas da linguística (Caregnato \& Mutti, 2006). Este conjunto de fenômenos, contextos, situações e ideologias formam uma rede de representações que alimentam uma determinada forma de pensamento social (Gomes, 2015).

\section{CONCLUSÕES}

A AD preocupa-se em compreender os sentidos que o sujeito manifesta em seu discurso e suas condições de produção. $O$ analista de discurso deve estar fidelizado em todas as etapas, visto que o processo é minucioso.

A utilização das entrevistas, genogramas e ecomapas oportunizam a expressão dos adolescentes, de seus vividos e de sua rede de cuidados.

O pesquisador ao utilizar a $A D$ na análise de dados qualitativos, deve ser coerente com as etapas, utilizando a transcrição, a leitura, a identificação de recursos ortográficos que movimentam o texto pelo emprego de legenda e as figuras de linguagem. Esse processo é fundamental para a construção das categorias analíticas da pesquisa. Os marcadores de produção de sentido auxiliam para que o analista possa chegar ao aprofundamento no texto, seu olhar deixa de ser superficial, utilizando os marcadores ortográficos e os dispositivos analíticos como a metáfora, a polissemia, a paráfrase e o interdiscurso.

A memória discursiva dos adolescentes que participaram deste estudo, os momentos de silenciamento, a memória latente, retomam sobre o desejo dos adolescentes serem vistos por suas possibilidades, para além das demandas de cuidados.

Por fim, sugere-se a utilização da AD pecheutiana como estratégia de análise de estudos qualitativos, capazes de olhar com profundidade para temas sensíveis na saúde do adolescente, que valorizam a dimensão histórica, social e cultural do cuidado.

\section{REFERÊNCIAS}

Brandão, H.H.N. (2012). Introdução à análise do discurso. 3ª̣ed. Campinas (SP): Editora da Unicamp.

Gomes, A.M.T. (2007). Do discurso às formações ideológica e imaginária: análise de discurso segundo Pêcheux e Orlandi. Rev enferm UERJ, 15(4), 555-62. 
Gomes, A. M. T. (2015). Análise de discurso francesa e teoria das representações sociais: algumas interfaces teórico-metodológicas. Psicologia e Saber Social, 4(1), 3-18.

Gonçalves, C.F. \& Freire, R.M.A.C. (2016). Análise do discurso e a fonoaudiologia: um diálogo promissor. Rev CEFAC. 18(4), 974-81.

Lima, D.W.C., Vieira, A.N., Gomes, A.M.T. \& Silveira, L.C. (2017). Historicidade, conceitos e procedimentos da análise do discurso. Rev enferm UERJ, 25, e12913.

Machado, A.C.C., Rossi, C.S., Rodrigues, B.M.R.D., Pacheco, S.T.A., Arantes, P.C.C. \& Rodrigues, B.R.D. (2016). Análise de discurso nas pesquisas de enfermagem na saúde da criança e do adolescente. Rev enferm UERJ, 24(6), e25737.

Orlandi, E.P. (2015). Análise do discurso: princípios e procedimentos. 12ª ed. Campinas (SP): Pontes Editores.

Pechêux, M. (2014). Semântica e Discurso: uma crítica à afirmação do óbvio. Tradução de Eni Puccinelli Orlandi et al. 5aㅡ ed. Campinas (SP): Editora Unicamp.

Rolim, A. C. A., Sancho, K. A., La-Rotta, E. I. G., Fernandez, M. R. B., Figueiredo, V. C. J., Friestino, J. K. O. \& Corrêa, C. R. S. (2018). Análise do discurso pecheutiana como referencial teórico e metodológico na saúde coletiva: revisão da literatura. Revista Psicologia, Diversidade e Saúde, 7(1), 149-160.

Schiavon, I. C. A., Oliveira, E. C., Andrade, S. C. \& Gonçalves, J. C. (2017). Produção científica sobre análise do discurso na enfermagem e referenciais teóricos utilizados. HOLOS, (05), 329-344. 